\section{New alate for North West study alay}

Due to COVID-19 the FGDP(UK) has had to reschedule its next Study Day. Originally planned for 13 November 2020 , the event will now take place on Saturday 27 March 2021. The venue is still the stunning Science + Industry Museum, in the heart of Manchester, where delegates will be joined by speakers lan Dunn and Serpil Djemal.

Ian Dunn is the Perio Lead for the Faculty of General Dental Practitioners and runs their short course in periodontics and leads the perio components of the FGDP Restorative Diploma. His sessions will focus on contemporary periodontal practice providing a modern understanding of aetiology, assessment and diagnosis, and looking at motivating patients to achieve high standards of home care to achieve non-surgical management of periodontal disease.

Serpil Djemal is actively involved in the acute and long term management of patients who have sustained traumatic dental injuries and is also the founder chairperson of Dental Trauma UK - a new charity set up to raise public and professional awareness in the prevention and management of traumatic dental injuries. Serpil will present 'Crash bang wallop - modern management of dental trauma' giving ALL members of the dental team a better understanding of the presentation and management of traumatic dental injuries with a focus on the management of dental fractures and the management of luxation injuries.

Delegates will, as usual, be joined by a large number of exhibitors and sponsors - giving them the chance to meet suppliers and find out about the latest innovations, plus, there will be a networking event after the main scientific programme.

Join the Faculty for six hours of verifiable CPD, world class speakers, and great networking opportunities. To book places for you and your team go to https://www.fgdp-nw.com/ book-manchester-study-day/.

\title{
DCPs' ANNUAL RENEWAL NOW OPEN
}

The Annual Renewal period for UK registered dental care professionals (DCPs) is now open and the deadline for completion is 31 July 2020 . To renew their registration, DCPs need to:

- Make their annual or end-of-cycle CPD statement

- Declare they have, or will have, appropriate indemnity in place

- Pay their Annual Retention Fee (ARF).

The quickest and easiest way to complete the Annual Renewal is through eGDC, and it takes only five minutes to register to use the service if not already set up.

GDC Executive Director, Registration and Corporate Resources, Gurvinder Soomal, said: 'We are very aware that Annual Renewal comes at a difficult time this year for DCPs, when many have been unable to work or have had difficulty accessing

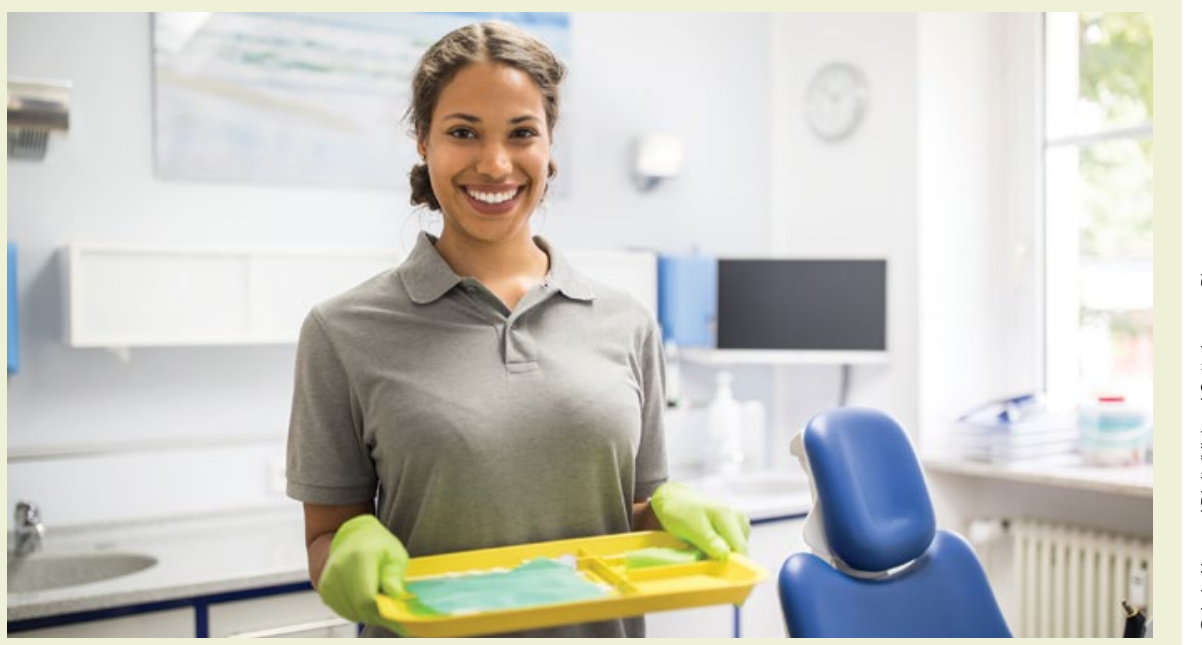

\section{BDA COMMITS TO TACKLING RACISM}

The British Dental Association (BDA) has set out its commitment to tackle racism and discrimination at all levels in dentistry, following international outcry initiated by the death of George Floyd in May.

The BDA will engage with black, Asian and minority ethnic (BAME) dentists, as part of a research project to establish the views of those involved both in its ranks and the wider profession, to identify clearly those areas where racial disparities and racism exist within dentistry and on the basis of this develop an evidence-based action plan to address them.

Despite the demographic changes in
CPD. Our records indicate that four out of five DCPs have already met the CPD requirements, but it is entirely possible that COVID-19 has prevented many DCPs from completing the required amount of CPD.

'While an essential part of Annual Renewal is to make an annual or end-ofcycles CPD statement, we have been clear that if professionals have a shortfall of completed CPD hours due to COVID-19, they will not be penalised for this. For anyone in this position, you still need to make the statement and we'll then be in touch to talk about next steps.'

The GDC provides further guidance and information about Annual Renewal on its website: https://www.gdc-uk.org/ registration/annual-renewal-and-fees.

Looking for CPD hours? BDJ Team offers ten free hours every year: https://go.nature. com/3gsKCaX.

the make-up of the dental profession, black people are still significantly underrepresented, accounting for only $1 \%$ of the GDC register. There is also evidence to suggest that BAME patients are less likely to attend the dentist. The reasons for this need to be clearly understood, so that all communities can have access to dental services on an equal footing. Public Health England analysis of the disparities in COVID-19 outcomes related to ethnicity and other factors have drawn renewed attention to health inequalities and dentist leaders have said these inequalities must be addressed in oral health as well. 